\title{
Claw Lesions Causing Clinical Lameness in Lactating Holstein Frisian Crossbred Cows
}

\author{
Umar Nazir Zahid, ${ }^{1}$ Swaran Singh Randhawa, ${ }^{2}$ Syed Ashaq Hussain, ${ }^{2}$ \\ Sarnarinder Singh Randhawa, ${ }^{3}$ Vishal Mahajan, ${ }^{4}$ and Kirti Dua ${ }^{2}$ \\ ${ }^{1}$ Department of Animal Husbandry, Jammu and Kashmir 190019, India \\ ${ }^{2}$ Department of Veterinary Medicine, Guru Angad Dev Veterinary and Animal Sciences University, Ludhiana, \\ Punjab 141004, India \\ ${ }^{3}$ Guru Angad Dev Veterinary and Animal Sciences University, Ludhiana, Punjab 141004, India \\ ${ }^{4}$ Animal Disease Research Centre, Guru Angad Dev Veterinary and Animal Sciences University, Ludhiana, Punjab 141004, India \\ Correspondence should be addressed to Syed Ashaq Hussain; draashiqhussain@gmail.com
}

Received 9 March 2014; Revised 2 June 2014; Accepted 24 June 2014; Published 14 July 2014

Academic Editor: William Ravis

Copyright @ 2014 Umar Nazir Zahid et al. This is an open access article distributed under the Creative Commons Attribution License, which permits unrestricted use, distribution, and reproduction in any medium, provided the original work is properly cited.

The objective of this study was to identify claw lesions causing clinical lameness in lactating Holstein Frisian (HF) crossbred cows in dairy cattle. Seventy dairy farmers were interviewed at the monthly meetings of Progressive Dairy Farmers Association of Ludhiana, Punjab, India. Ten dairy farms were randomly selected as per probability proportional to size and a total of 450 lactating HF crossbred cows were taken into the study. All the lactating cows were scored for locomotion and rear leg view index. Trimming was done in all the clinically lame animals (animals with locomotion scores 2 and 3) and equal number of animals selected randomly from those with locomotion scores 0 and 1 . Various claw lesions were evaluated in both the groups. There was a significant relationship between locomotion score and rear leg view index to identify lameness. Sole ulcers and white line fissures were the lesions responsible for clinical lameness. Other lesions did not cause clinical lameness but increased the asymmetry in lactating HF crossbred cows. Both locomotion score and rear leg view index could be reliably used to identify clinical lameness in lactating cattle.

\section{Introduction}

Lameness is one of the greatest economic concerns of present day dairy industry. The major ill effects of lameness include pain, distress, loss in production, a negative impact on reproductive performance, and an increased risk of culling [1]. It is reported that $60 \%$ of herd may become lame at least once a year [2] and about $90-99 \%$ of lameness incidents occur due to claw lesions $[3,4]$. Clinical lameness is comparatively more concerned because of high rate of culling [5] and marked reduction in milk yield [6].

The mere presence of a lesion is not associated with clinical lameness [7] but it also depends on severity of foot lesion. Only a few studies have investigated the relationship between locomotion score and the type of foot lesion present [8-10]. Sole ulcer, double sole, interdigital purulent inflammation, and severe stages of digital dermatitis have been associated with clinical lameness $[7,11]$. Keeping in view the increasing population of HF crossbred cows in Punjab, India, this study seemed to be necessary. The present study was designed to identify the foot lesions responsible for clinical lameness in lactating HF crossbred cattle. Another objective was to evaluate the reliability of locomotion score and rear leg view index for identifying clinical lameness.

\section{Materials and Methods}

2.1. Selection of Animals. Seventy farmers were interviewed at the monthly meetings of Progressive Dairy Farmers Association of Ludhiana, Punjab, India. The farmers were questioned about general management, housing system, claw trimming 
TABLE 1: Association between locomotion scores (2 and 3) and various lesions.

\begin{tabular}{lccccc}
\hline Lesions & Coefficients & Standard error & $P$ value & Lower 95\% & Upper 95\% \\
\hline Intercept & 2.107 & 0.116 & 0.00 & 1.876 & -0.031 \\
HE & -0.0029 & 0.014 & 0.842 & -0.051 & 0.026 \\
SH & 0.0027 & 0.027 & 0.921 & -0.11 & 0.056 \\
WLH & 0.1100 & 0.11 & 0.322 & -0.015 & 0.329 \\
SA & 0.0117 & 0.014 & 0.392 & -0.103 & 0.039 \\
US & -0.0047 & 0.049 & 0.925 & -0.104 & 0.094 \\
OS & 0.0391 & 0.071 & 0.586 & -0.499 & 0.182 \\
OH & -0.0465 & 0.226 & 0.838 & 0.002 & 0.106 \\
WLF & $0.0707^{*}$ & 0.034 & 0.044 & -0.38 & 0.516 \\
IDH & 0.0680 & 0.224 & 0.762 & 0.184 & 0.773 \\
SU & $0.478^{*}$ & 0.147 & 0.002 &
\end{tabular}

* Significant at $P \leq 0.05$.

HE: heel erosion, SH: sole haemorrhage, WLH: white line haemorrhage, SA: sole avulsion, US: underrun sole, OS: overgrown sole, OH: overgrown hoof, WLF: white line fissure, IDH: interdigital hyperplasia, SU: sole ulcer.

TABLE 2: Association between locomotion scores ( 0 and 1$)$ and various lesions.

\begin{tabular}{|c|c|c|c|c|c|}
\hline Lesions & Coefficients & Standard error & $P$ value & Lower 95\% & Upper $95 \%$ \\
\hline Intercept & 0.71 & 0.088 & 0.000 & 0.537 & 0.890 \\
\hline $\mathrm{HE}$ & 0.015 & 0.013 & 0.263 & -0.012 & 0.042 \\
\hline $\mathrm{SH}$ & 0.010 & 0.035 & 0.780 & -0.060 & 0.080 \\
\hline WLH & 0.006 & 0.093 & 0.948 & -0.180 & 0.192 \\
\hline SA & 0.003 & 0.026 & 0.894 & -0.049 & 0.055 \\
\hline US & 0.068 & 0.044 & 0.128 & -0.020 & 0.157 \\
\hline OS & -0.146 & 0.086 & 0.095 & -0.317 & 0.026 \\
\hline $\mathrm{OH}$ & -0.741 & 0.427 & 0.088 & -1.597 & 0.115 \\
\hline WLF & 0.039 & 0.143 & 0.784 & -0.247 & 0.325 \\
\hline IDH & 0.021 & 0.095 & 0.824 & -0.169 & 0.211 \\
\hline
\end{tabular}

HE: heel erosion, SH: sole haemorrhage, WLH: white line haemorrhage, SA: sole avulsion, US: underrun sole, OS: overgrown sole, OH: overgrown hoof, WLF: white line fissure, IDH: interdigital hyperplasia.

routines, milk production, nutrition, number of lame animals, presence of lameness chute, and knowledge about lameness and its ill effects. Among these seventy enrolled farmers, ten farms were selected randomly as per probability proportional to size sampling [12]. A total of 450 lactating $\mathrm{HF}$ cross bred cows were included in the study. All these animals were kept in loose housing system with provision of both soft and concrete flooring. The average milk yield of these animals was 3000-4000 litres/lactation. Majority of the animals were fed maize silage along with concentrate feed @ 400 gram for every kilogram of milk production.

2.2. Locomotion Score and Rear Leg View Index (RLVI). All the ten farms were visited after the morning milking. Locomotion score and rear leg view index of all the 450 animals were evaluated independently by two observers, working together. For locomotion score, the cows were allowed to walk on a flat surface for up to 30 meters. Locomotion score of each animal was assessed on a five-point scale as described by Wells et al. [13]. RLVI of each animal was recorded as normal/score 0 (when there was no inward knuckling of hocks and hocks were straight) and cow hock/score 1 (when there was inward knuckling of hocks), when observed from rear side [14].

2.3. Hoof Examination. Hoof trimming was done as per standard procedure [14] and different foot lesions were observed in all the lame animals (locomotion scores 2 and 3 ) and equal number of animals selected randomly from those with locomotion scores 0 and 1 [12]. Each animal was properly restrained in trimming chute and then each foot was examined for any lesion before and after paring a layer of approximately $1 \mathrm{~mm}$ of horn from the weight bearing surface. Heel erosions, sole haemorrhages, sole avulsions, white line haemorrhages, and white line fissures were scored for severity on hoof maps, as per Randhawa et al. [15]. The rest of the foot lesions, namely, sole ulcers, underrun soles, double soles, overgrown hooves, overgrown soles, and interdigital hyperplasia, were categorized as 1 (when present) and 0 (when absent) [14].

2.4. Statistical Analysis. In order to identify the lesions responsible for lameness, regression analysis was carried out using statistical package for social sciences (SPSS for windows 
TABLE 3: Correlation between lesions within cows having locomotion scores 2 and 3 (first row $=$ correlation coefficient, second row $=$ probability value).

\begin{tabular}{|c|c|c|c|c|c|c|c|c|c|c|}
\hline Lesion & $\mathrm{HE}$ & $\mathrm{SH}$ & WLH & SA & US & OS & $\mathrm{OH}$ & WLF & IDH & $\mathrm{SU}$ \\
\hline \multirow{2}{*}{$\mathrm{HE}$} & 1 & & & & & & & & & \\
\hline & . & & & & & & & & & \\
\hline \multirow{2}{*}{ SH } & 0.1 & 1 & & & & & & & & \\
\hline & 0.201 & . & & & & & & & & \\
\hline \multirow{2}{*}{ WLH } & -0.019 & -0.047 & 1 & & & & & & & \\
\hline & 0.332 & 0.346 & . & & & & & & & \\
\hline \multirow{2}{*}{ SA } & $0.26^{*}$ & 0.008 & -0.07 & 1 & & & & & & \\
\hline & 0.013 & 0.473 & 0.277 & . & & & & & & \\
\hline \multirow{2}{*}{ US } & $0.224^{*}$ & 0.003 & -0.025 & -0.083 & 1 & & & & & \\
\hline & 0.029 & 0.49 & 0.415 & 0.243 & . & & & & & \\
\hline \multirow{2}{*}{ OS } & -0.051 & -0.163 & 0.125 & -0.083 & $0.299^{* *}$ & 1 & & & & \\
\hline & 0.333 & 0.084 & 0.145 & 0.244 & 0.005 & . & & & & \\
\hline \multirow{2}{*}{$\mathrm{OH}$} & $0.315^{* *}$ & 0.025 & -0.041 & -0.011 & 0.096 & -0.062 & 1 & & & \\
\hline & 0.003 & 0.415 & 0.364 & 0.462 & 0.211 & 0.301 & . & & & \\
\hline \multirow{2}{*}{ WLF } & -0.02 & -0.076 & 0.082 & 0.123 & 0.029 & 0.134 & -0.081 & 1 & & \\
\hline & 0.433 & 0.26 & 0.244 & 0.149 & 0.404 & 0.128 & 0.249 & . & & \\
\hline \multirow{2}{*}{ IDH } & -0.121 & 0.084 & -0.084 & -0.053 & 0.089 & 0.033 & -0.028 & -0.087 & 1 & \\
\hline & 0.154 & 0.241 & 0.239 & 0.327 & 0.227 & 0.391 & 0.406 & 0.233 & . & \\
\hline \multirow{2}{*}{ SU } & -0.059 & -0.104 & 0.041 & -0.181 & -0.189 & -0.028 & -0.039 & $0.253^{* *}$ & -0.081 & 1 \\
\hline & 0.31 & 0.191 & 0.364 & 0.062 & 0.055 & 0.406 & 0.37 & 0.015 & 0.249 & . \\
\hline
\end{tabular}

${ }^{*}$ Significant at 0.05 level; ${ }^{* *}$ significant at 0.01 level.

HE: heel erosion, SH: sole haemorrhage, WLH: white line haemorrhage, SA: sole avulsion, US: underrun sole, OS: overgrown sole, OH: overgrown hoof, WLF: white line fissure, IDH: interdigital hyperplasia, SU: sole ulcer.

TABLE 4: Correlation between lesions within cows having locomotion scores 0 and 1 (first row $=$ correlation coefficient, second row $=$ probability value).

\begin{tabular}{|c|c|c|c|c|c|c|c|c|c|}
\hline Lesion & $\mathrm{HE}$ & $\mathrm{SH}$ & WLH & SA & US & OS & $\mathrm{OH}$ & WLF & IDH \\
\hline \multirow{2}{*}{$\mathrm{HE}$} & 1 & & & & & & & & \\
\hline & $\cdot$ & & & & & & & & \\
\hline \multirow{2}{*}{$\mathrm{SH}$} & 0.151 & 1 & & & & & & & \\
\hline & 0.225 & . & & & & & & & \\
\hline \multirow{2}{*}{ WLH } & 0.025 & $0.45^{* *}$ & 1 & & & & & & \\
\hline & 0.842 & 0 & . & & & & & & \\
\hline \multirow{2}{*}{ SA } & 0.093 & 0.241 & 0.17 & 1 & & & & & \\
\hline & 0.456 & 0.051 & 0.173 & . & & & & & \\
\hline \multirow{2}{*}{ US } & -0.062 & -0.107 & -0.141 & -0.096 & 1 & & & & \\
\hline & 0.623 & 0.392 & 0.26 & 0.445 & . & & & & \\
\hline \multirow{2}{*}{ OS } & $0.386^{* *}$ & -0.038 & -0.081 & -0.016 & 0.205 & 1 & & & \\
\hline & 0.001 & 0.764 & 0.516 & 0.899 & 0.099 & . & & & \\
\hline \multirow{2}{*}{$\mathrm{OH}$} & -0.053 & 0.08 & 0.162 & -0.039 & 0.008 & 0.103 & 1 & & \\
\hline & 0.672 & 0.522 & 0.193 & 0.759 & 0.951 & 0.412 & . & & \\
\hline \multirow{2}{*}{ WLF } & 0.109 & 0.011 & -0.114 & 0.097 & 0.062 & 0.101 & 0.095 & 1 & \\
\hline & 0.384 & 0.929 & 0.364 & 0.438 & 0.622 & 0.422 & 0.45 & . & \\
\hline \multirow{2}{*}{ IDH } & 0.034 & 0.014 & -0.119 & 0.146 & 0.143 & 0.006 & 0.044 & $0.884^{* *}$ & 1 \\
\hline & 0.785 & 0.91 & 0.343 & 0.242 & 0.254 & 0.964 & 0.728 & 0 & . \\
\hline
\end{tabular}

** Significant at 0.01 level.

HE: heel erosion, SH: sole haemorrhage, WLH: white line haemorrhage, SA: sole avulsion, US: underrun sole, OS: overgrown sole, OH: overgrown hoof, WLF: white line fissure, IDH: interdigital hyperplasia. 


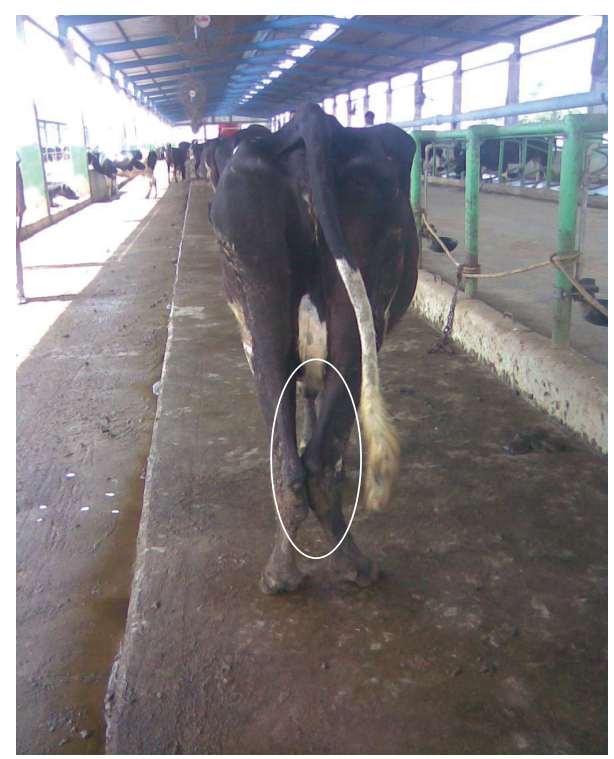

FIGURE 1: Cow hock: rear leg view index.

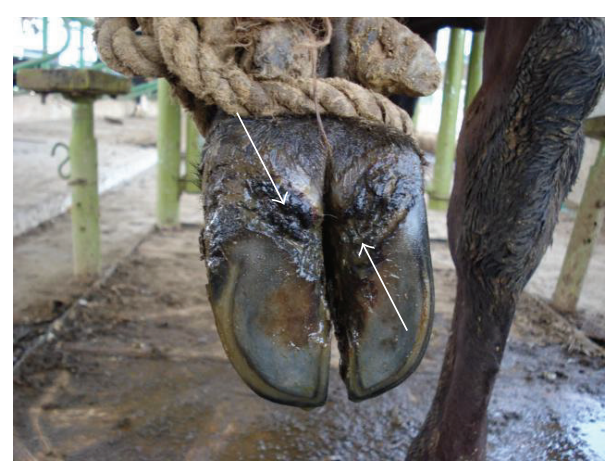

Figure 2: Heel erosion.

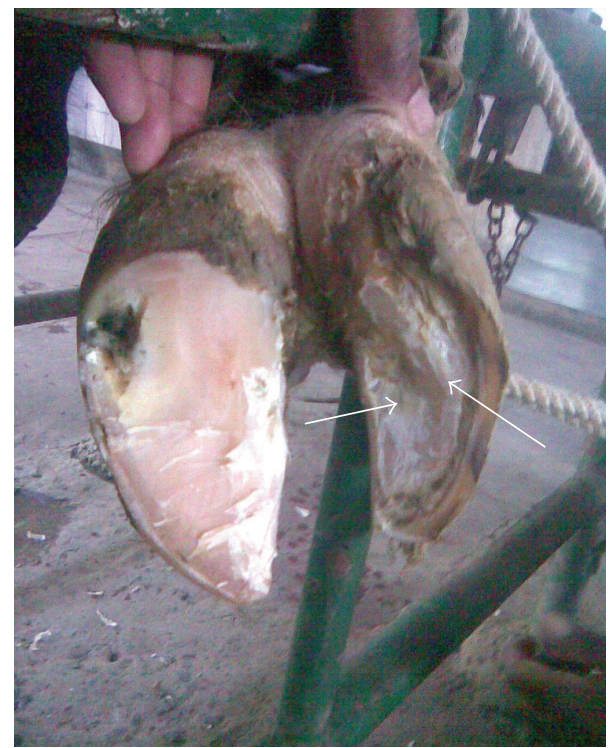

Figure 3: Sole avulsion.

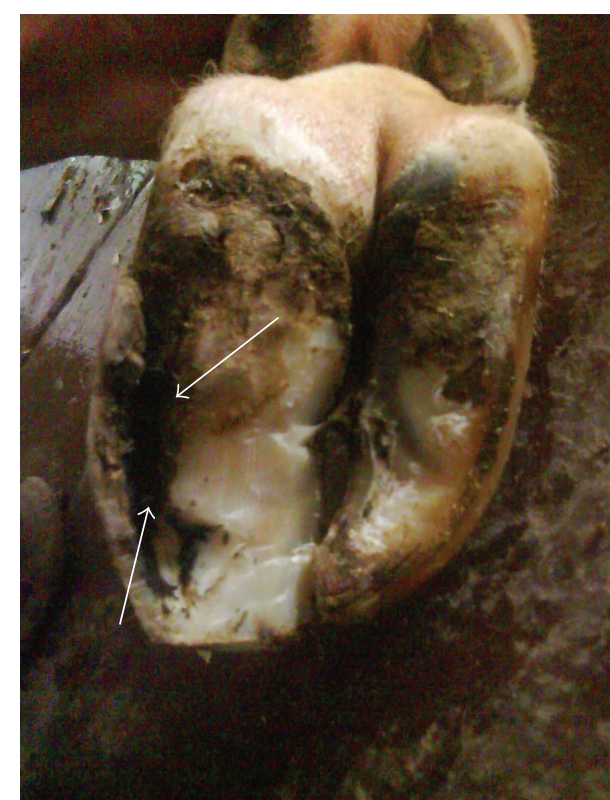

FIGURE 4: White line fissure.

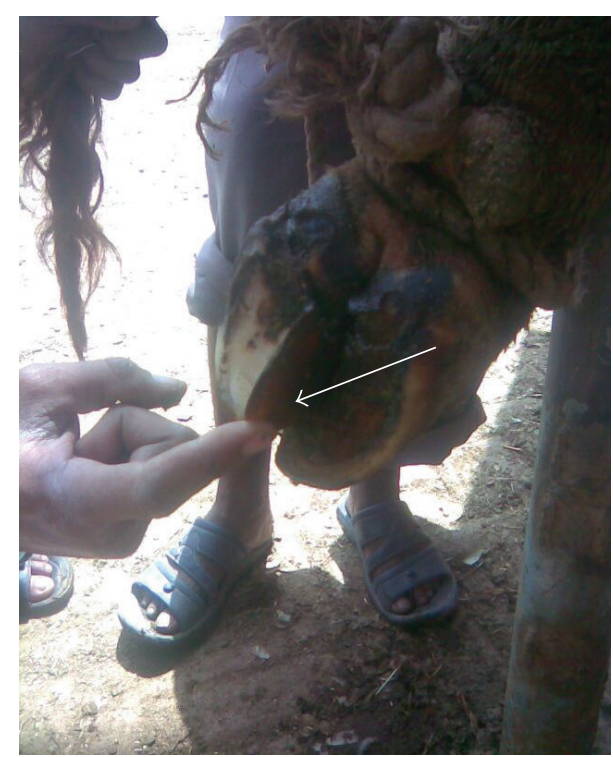

Figure 5: Underrun sole.

version 11-0-1; SPSS Inc, Chicago, Illinois). The correlation between different lesions within cow was investigated and correlated at $P \leq 0.05$ and $P \leq 0.01$. The relationship between locomotion score and rear leg view was analyzed by Chi square analysis. The reliability of locomotion scores assigned by two observers was analyzed by calculating Spearman's rank correlation coefficient.

\section{Results}

Out of 450 cows, $8.6 \%(n=39), 73.7 \%(n=332), 12.8 \%$ $(n=58)$, and $4.6 \%(n=21)$ were having $0,1,2$, and 3 locomotion score, respectively. The association between 


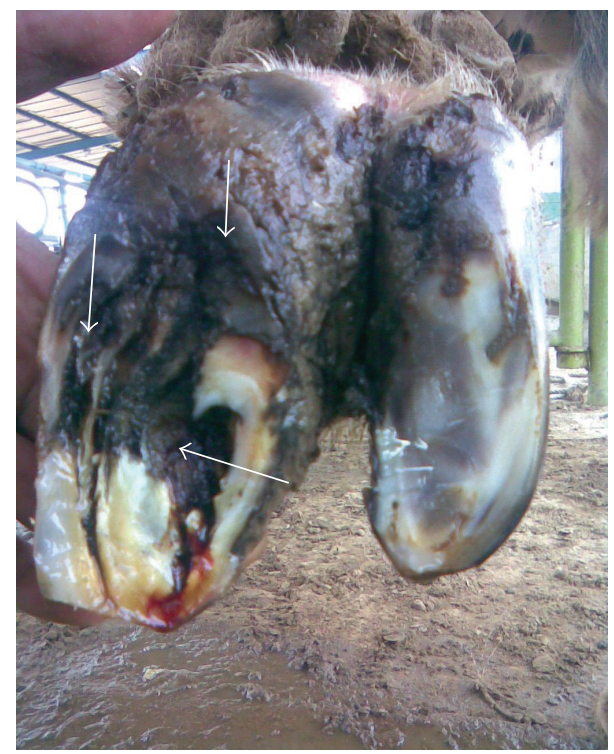

FIgURE 6: Heel erosion, white line fissure, and underrun sole.

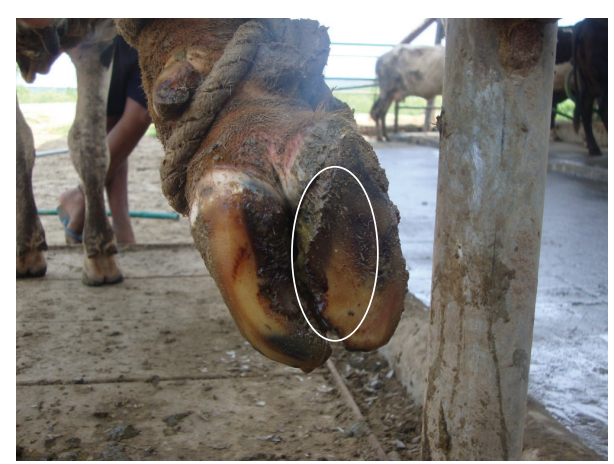

Figure 7: Overgrown sole.

locomotion score and various lesions is presented in Tables 1 and 2 and the photographs of various lesions and RLVI are depicted in Figures 1, 2, 3, 4, 5, 6, 7, 8, 9, and 10. Heel erosions were present in about $70 \%$ of the animals with locomotion score 2 and about $28 \%$ of the animals with locomotion score 3 (Figures 11(a) and 11(b)) but they failed to cause apparent lameness. In contrast, sole ulcers and white line fissures had a close association with poor locomotion, with figures of $11.11 \%$ and $88.89 \%$ for sole ulcer and $15.58 \%$ and $84.42 \%$ for white line fissures, for locomotion scores 2 and 3 , respectively (Figure 11(b)). All the other lesions did not cause clinical lameness but tend to increase asymmetry (Table 1 ).

In case of normal animals (locomotion score 0 ) and asymmetric animals (locomotion score 1) the presence of lesions was associated with increased locomotion score. In other words the degree of asymmetry was more in animals with foot lesions (Figures 12(a) and 12(b)). However, despite the presence of lesions, these animals were not clinically lame.

In clinically lame cows (locomotion scores 2 and 3 ) there was a significant correlation between sole avulsions and heel erosions (0.26; $P \leq 0.05)$, underrun soles and heel erosions

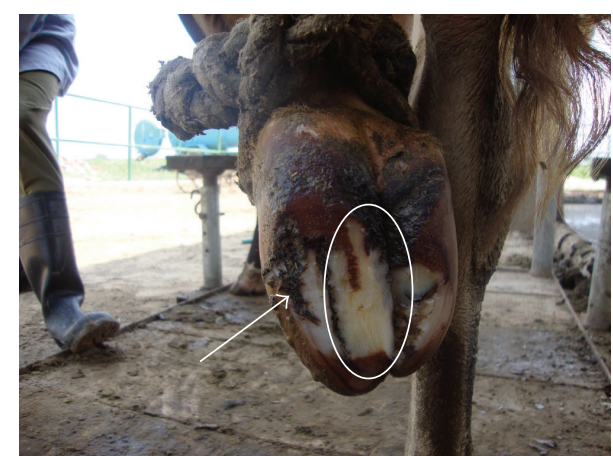

FIGURE 8: Overgrown sole and white line fissure.

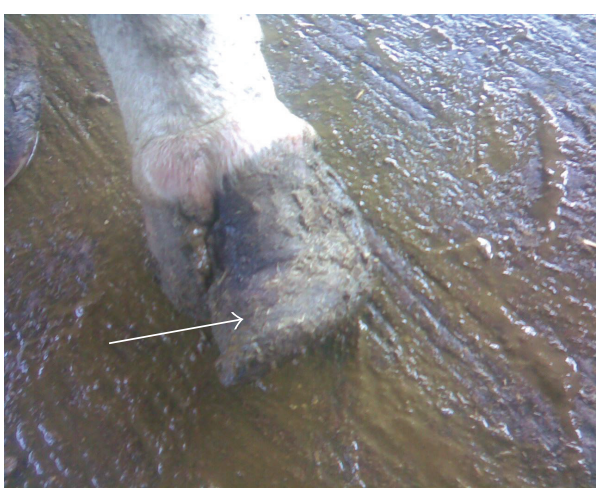

Figure 9: Overgrown hoof.

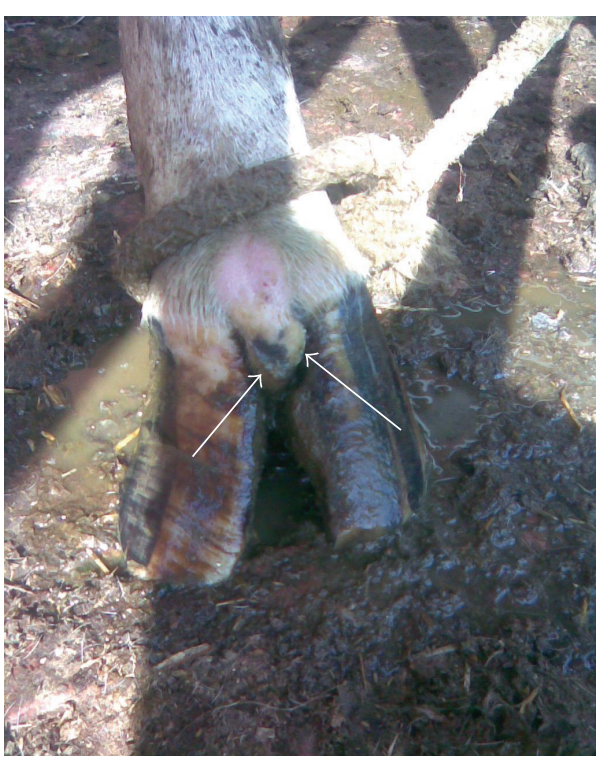

FIGURE 10: Interdigital hyperplasia.

$(0.224 ; P \leq 0.05)$, overgrown hooves and heel erosions ( 0.315 ; $P \leq 0.01)$, overgrown sole and underrun soles $(0.299 ; P \leq$ $0.01)$, and sole ulcers and white line fissures $(0.253 ; P \leq 0.01)$ (Table 3 ). In cows with locomotion scores 0 and 1 there was a significant correlation between overgrown soles and heel erosions $(0.386 ; P \leq 0.01)$, white line haemorrhages and sole 


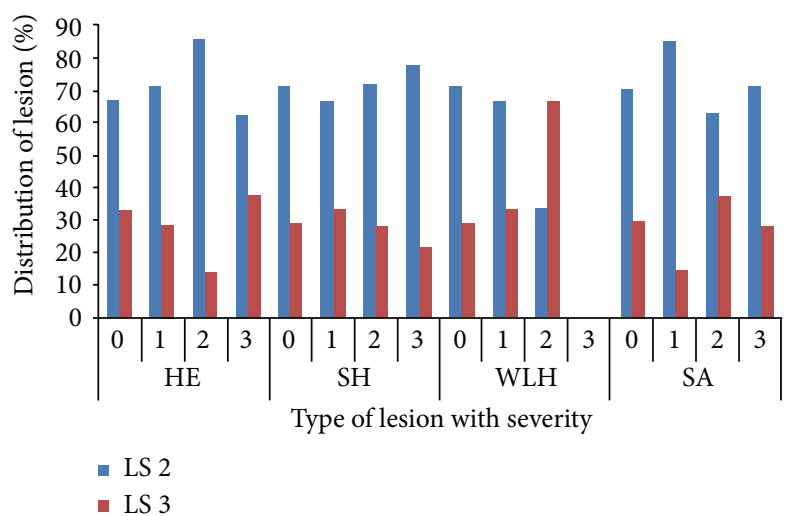

(a)

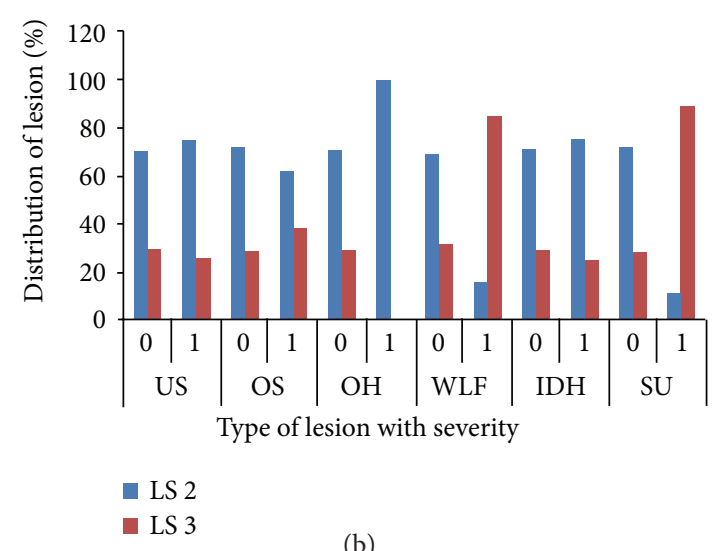

(b)

FIGURE 11: (a) Distribution of severities of lesions in cows with locomotion score 2 and 3, HE: heel erosion, SH: sole haemorrhage, WLH: white line haemorrhage, SA: sole avulsion, LS: locomotion score. (b) Distribution of severities of lesions in cows with locomotion score 2 and 3, US: under run sole, OS: overgrown sole, OH: overgrown hoof, WLF: white line fissure, IDH: interdigital hyperplasia, SU: Sole ulcer, LS: locomotion score.

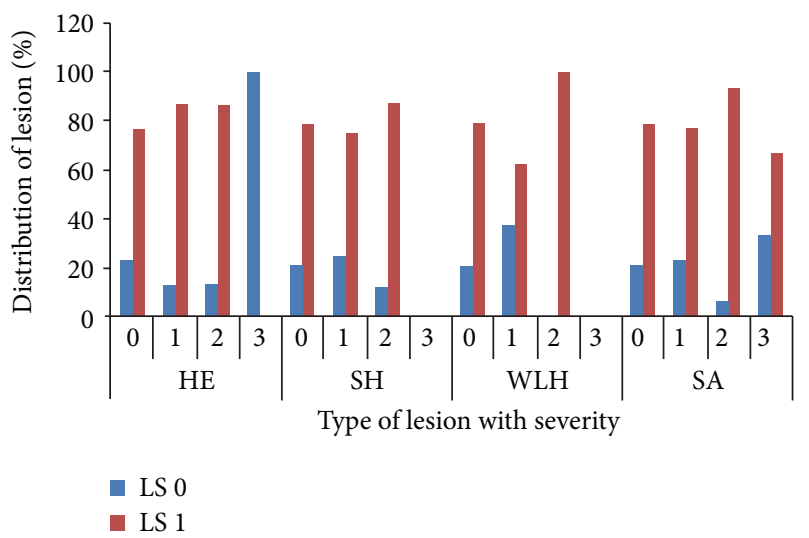

(a)

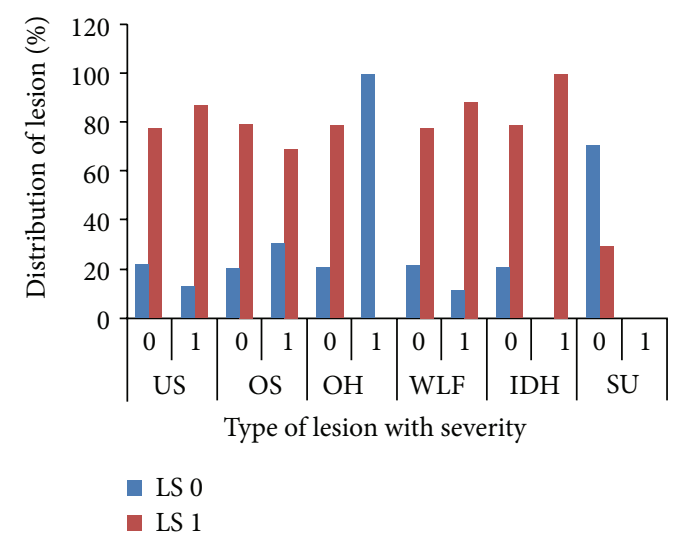

(b)

Figure 12: (a) Distribution of severities of lesions in cows with locomotion scores 0 and 1, HE: heel erosion, SH: sole haemorrhage, WLH: white line haemorrhage, SA: sole avulsion, LS: locomotion score. (b) Distribution of severities of lesions in cows with locomotion scores 0 and 1, US: underrun sole, OS: overgrown sole, OH: overgrown hoof, WLF: white line fissure, IDH: interdigital hyperplasia, SU: sole ulcer, LS: locomotion score.

haemorrhages $(0.45 ; P \leq 0.01)$, and interdigital hyperplasia and white line fissures $(0.884 ; P \leq 0.01)$ (Table 4$)$.

There was a significant relationship between locomotion score and RLVI $\left(\chi^{2}=4.87 ; P \leq 0.05\right.$ for locomotion scores 2 and $3 ; \chi^{2}=12.95 ; P \leq 0.05$ for locomotion scores 0 and 1 ) to identify lameness. Spearman's rank correlation coefficient for locomotion score from two observers was $0.637(P \leq 0.01)$ and that for RLVI was $0.753(P \leq 0.01)$.

\section{Discussion}

In the present study, despite the presence of lesions in the animals with locomotion scores 0 and 1 , these animals did not show clinical lameness. The reason for this might be that several claw and digital lesions do not seem to inflict sufficient pain to cause clinical lameness [16]. Also, the individual susceptibility to foot lesions, pain, and resulting lameness vary from animal to animal [17]. Furthermore the potentially painful corium insult occurs several weeks before the lesions are visible in the sole [18]. So, ignoring these cows with lesions in the feet may reduce the probability of detecting risks for lesion development by misclassifying these cows as nonlame in spite of having lesions in feet.

From Table 3, it can be inferred that presence of sole avulsions, underrun soles, and overgrown hooves increased the chances of occurrence of heel erosions; presence of overgrown soles increased the chances of underrun soles; and presence of sole ulcers increased the chances of occurrence of white line fissures. The association between underrun sole and heel erosions may be attributed to their common aetiopathogenesis of subclinical laminitis [19]. A disturbance of microvasculature of the corium results in the escape of blood components into the tubules of the horn of the sole and bulb. As recovery occurs and sound horn is produced, 
the event is recorded as a blood strained stratum. As the new horn grows, the haemorrhagic stratum moves towards the surface, and during wear (or if horn is pared) it appears in the substance of the horn until it is worn away. A haemorrhagic stratum often terminated as a groove on the heel or under running of the sole. This underrunning until avulsed is observed as underrun soles. But if the sole horn quality is poor due to improper nutrition/mineralization the soles may get avulsed leading to sole avulsions [19].

The correlation between overgrown hooves and heel erosions may be attributed to altered balance of the claw with heel erosions leading to more weight bearing on the toes, leading to overgrowth of hooves. The association between underrun soles and overgrown soles could be due to possible damage to the axial solar part of the medial claw initiating the development of underrun sole [19], because most of the overgrown soles were present in the lateral hind claws. The association between sole ulcer and white line fissure may be due to the fact that both appear as a sequel to sole haemorrhages and white line haemorrhages, respectively, which are common lesions associated with subclinical laminitis. Subclinical laminitis causes damage either in lamina portion of white line or in the sole bulb area, the common site of sole ulcer. The significant correlation between sole ulcers and white line fissures and poor locomotion in the present study was in concurrence with that of Tadich et al. [7]. Clarkson et al. [20] also observed that sole ulcer and white line disease were the lesions responsible for lameness while another study [21] demonstrated that the skin lesions, namely, digital dermatitis and interdigital phlegmon, were the important cause of lameness. Similar to previous studies $[10,22]$ heel erosions and sole haemorrhages were not associated with locomotion score. Correlation between sole ulcer and double sole has been reported previously $[7,23]$ but no such correlation was observed in our study.

In normal (lameness score 0) and asymmetric animals (lameness score 1), the presence of overgrown soles increased the chances of heel erosions or vice versa and white line haemorrhages increased the chances of occurrence of sole haemorrhages or vice versa. The possible reason for these correlations could be similar to that for the clinically lame animals. White line fissures may have increased the proximity of hooves and interdigital space to the underfoot manure/slurry and may have led to interdigital dermatitis and in turn interdigital hyperplasia [19].

The significant correlation between locomotion score and RLVI indicated that the placement of claws gets disturbed due to pain of different lesions, leading to improper weight bearing. As more lesions were observed in hind lateral claws, the animals shift their weight to medial claws to relieve the pain in lateral claws resulting in inward knuckling of hocks (cow hock rear leg view). This change in the rear leg view conformation along with the type of lesion present may render the animal asymmetric or lame. Thus, a significant correlation between two indices indicates that both locomotion score and RLVI can be reliably used to identify clinical lameness on dairy farms, despite the subjective nature of clinical diagnosis.

\section{Conclusions}

It was concluded that sole ulcers and white line fissures were the lesions responsible for clinical lameness in lactating HF crossbred cows. Other lesions do not cause clinical lameness but tend to increase asymmetry in dairy cows. The presence of sole avulsions, underrun soles, and overgrown hooves increased the chances of occurrence of heel erosions; presence of overgrown soles and white line fissures increased the chances of occurrence of underrun soles and sole ulcers, respectively. Locomotion score can be reliably used to identify clinical lameness in dairy cattle.

\section{Conflict of Interests}

The authors declare that there is no conflict of interests regarding the publication of this paper.

\section{Acknowledgment}

The authors would like to thank Dr. A. S. Nanda, Director of Research, Guru Angad Dev Veterinary and Animal Sciences University, Ludhiana, India, for providing the research facilities.

\section{References}

[1] K. O'Callaghan, "Lameness and associated pain in cattlechallenging traditional perceptions," In Practice, vol. 24, no. 4, pp. 212-219, 2002.

[2] J. J. Vermunt, "Herd lameness-a review," in Proceedings of the 13th International Symposium and 5th Conference on Lameness in Ruminants, vol. 18, pp. 3-18, Maribor, Slovenija, 2004.

[3] J. Hernandez, J. K. Shearer, and D. W. Webb, "Effect of lameness on milk yield in dairy cows," Journal of the American Veterinary Medical Association, vol. 220, no. 5, pp. 640-644, 2002.

[4] S. R. Van Amstel and J. K. Shearer, "Review of pododermatitis circumscripta (ulceration of the sole) in dairy cows," Journal of Veterinary Internal Medicine, vol. 20, no. 4, pp. 805-811, 2006.

[5] P. J. Rajala-Schultz and Y. T. Gröhn, "Culling of dairy cows part I. Effects of diseases on culling in Finnish Ayrshire cows," Preventive Veterinary Medicine, vol. 41, no. 2-3, pp. 195-208, 1999.

[6] L. E. Green, V. J. Hedges, Y. H. Schukken, R. W. Blowey, and A. J. Packington, "The impact of clinical lameness on the milk yield of dairy cows," Journal of Dairy Science, vol. 85, no. 9, pp. 2250-2256, 2002.

[7] N. Tadich, E. Flor, and L. Green, "Associations between hoof lesions and locomotion score in 1098 unsound dairy cows," Veterinary Journal, vol. 184, no. 1, pp. 60-65, 2010.

[8] T. Manske, J. Hultgren, and C. Bergsten, "The effect of claw trimming on the hoof health of Swedish dairy cattle," Preventive Veterinary Medicine, vol. 54, no. 2, pp. 113-129, 2002.

[9] K. A. O’Callaghan, P. J. Cripps, D. Y. Downham, and R. D. Murray, "Subjective and objective assessment of pain and discomfort due to lameness in dairy cattle," Animal Welfare, vol. 12, no. 4, pp. 605-610, 2003.

[10] F. C. Flower and D. M. Weary, "Effect of hoof pathologies on subjective assessments of dairy cow gait," Journal of Dairy Science, vol. 89, no. 1, pp. 139-146, 2006. 
[11] S. L. Berry, "Infectious diseases of the Bovine claw," in Proceedings of the 14th International Symposium and 6th Conference on Lameness in Ruminants, pp. 52-57, Colonia del Sacremento, Uruguay, 2006.

[12] M. Thrushfield, Veterinary Epidemiology, Blackwell, London, UK, 2007.

[13] S. J. Wells, A. M. Trent, W. E. Marsh, and R. A. Robinson, "Prevalence and severity of lameness in lactating dairy cows in a sample of Minnesota and Wisconsin herds," Journal of the American Veterinary Medical Association, vol. 202, no. 1, pp. 7882, 1993.

[14] E. Toussaint Raven, Cattle Foot Care and Claw Trimming, Farming Press Limited, Ipswich, UK, 1989.

[15] S. S. Randhawa, K. Dua, C. S. Randhawa, S. S. Randhawa, and S. K. Munshi, "Effect of biotin supplementation on hoof health and ceramide composition in dairy cattle," Veterinary Research Communications, vol. 32, no. 8, pp. 599-608, 2008.

[16] T. Manske, J. Hultgren, and C. Bergsten, "Prevalence and interrelationships of hoof lesions and lameness in Swedish dairy cows," Preventive Veterinary Medicine, vol. 54, no. 3, pp. 247263, 2002.

[17] J. J. Vermunt, "Risk factors of laminitis an overview," in Proceedings of the 6th International Symposium on Disorders of Ruminant Digit and International Conference on Bovine Lameness, pp. 34-45, Parma, Italy, 2000.

[18] K. A. Leach, D. N. Logue, S. A. Kempson, J. E. Offer, H. E. Ternent, and J. M. Randall, "Claw lesions in dairy cattle: development of sole and white line haemorrhages during the first lactation," The Veterinary Journal, vol. 154, no. 3, pp. 215225, 1997.

[19] S. S. Randhawa, Prevalence, biomechanics, pathogenesis and clinico-therapeutic studies on foot lameness in dairy animals [PhD Dissertation], Guru AngadDev Veterinary and Animal Sciences University, Ludhiana, India, 2006.

[20] M. J. Clarkson, D. Y. Downham, W. B. Faull et al., "Incidence and prevalence of lameness in dairy cattle," Veterinary Record, vol. 138, no. 23, pp. 563-567, 1996.

[21] J. E. Offer, D. McNulty, and D. N. Logue, "Observations of lameness, hoof conformation and development of lesions in dairy cattle over four lactations," Veterinary Record, vol. 147, no. 4, pp. 105-109, 2000.

[22] D. N. Logue, J. E. Offer, and J. J. Hyslop, "Relationship of diet, hoof type and locomotion score with lesions of the sole and white line in dairy cattle," Animal Production, vol. 59, pp. 173181, 1994.

[23] N. Capion, S. M. Thamsborg, and C. Enevoldsen, "Prevalence and severity of foot lesions in Danish Holstein heifers through first lactation," Veterinary Journal, vol. 182, no. 1, pp. 50-58, 2009. 

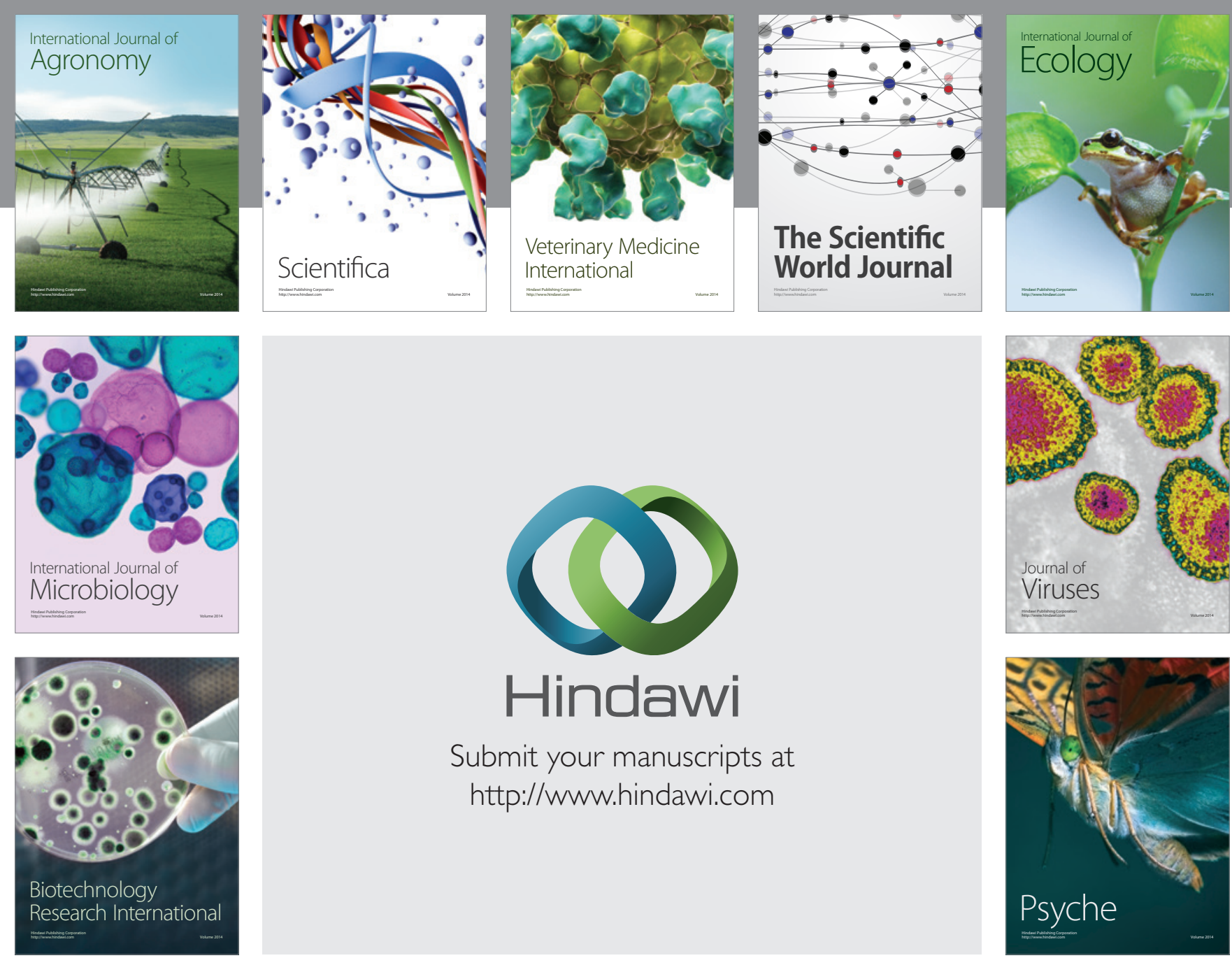

Submit your manuscripts at http://www.hindawi.com
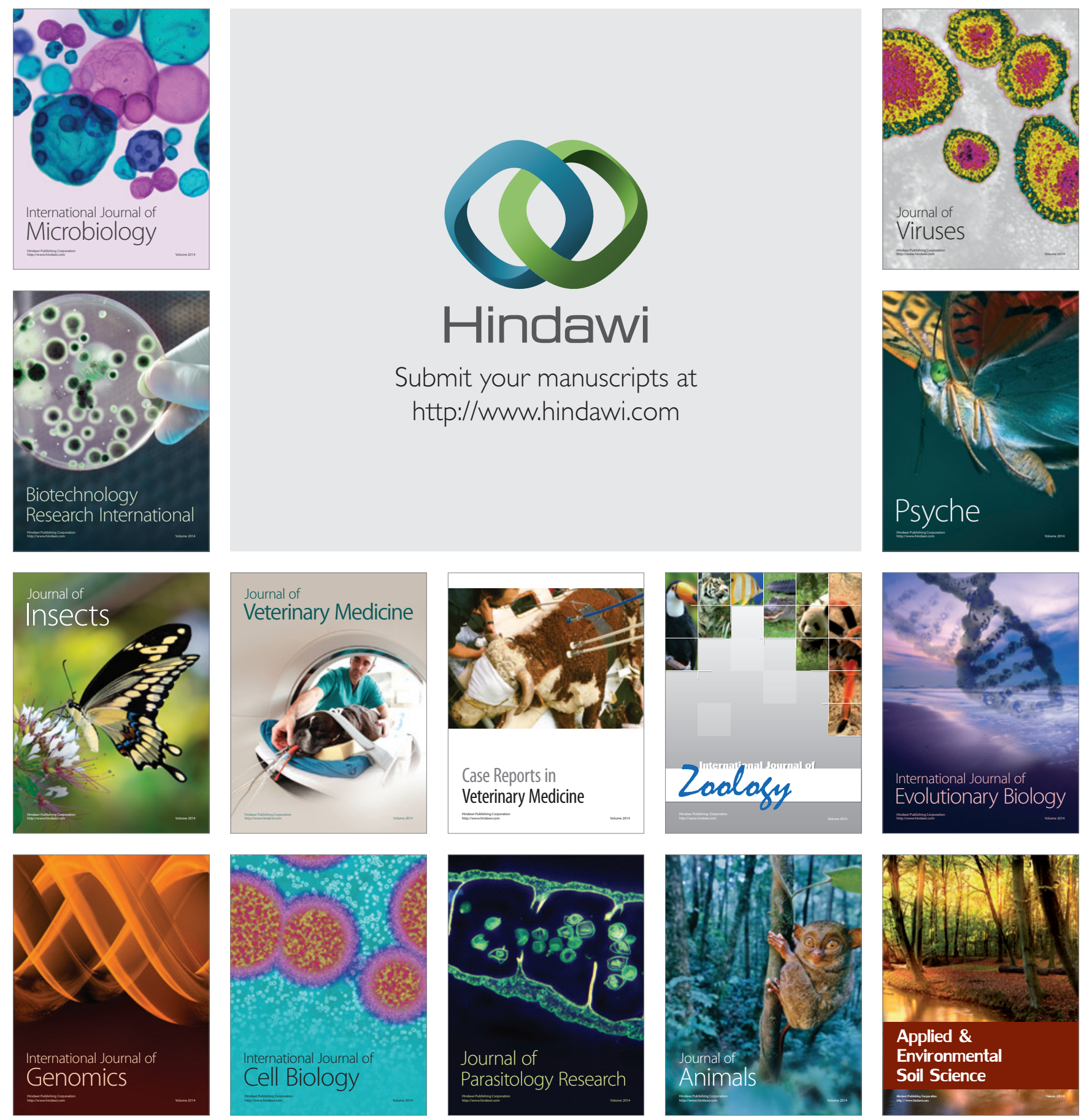